\title{
artigos
}

DOI: 10.11606/issn.2318-8855.v6i6p15-43

\section{O debate legislativo sobre a assistência psiquiátrica na Primeira República'}

José Roberto Silvestre Saiol $^{*}$

Resumo: Este trabalho investiga os debates envolvidos no processo de negociação social e política que se fazem presentes durante a elaboração de documentos legislativos voltados para a área da assistência psiquiátrica no contexto brasileiro da Primeira República, considerando-se dois espaços sociais específicos e sua respectiva documentação: os Anais da Câmara dos Deputados, relativos aos anos de 1903 e 1926; e as atas da Sociedade Brasileira de Psiquiatria, Neurologia e Medicina Legal (SBNPML) referentes ao recorte temporal privilegiado (1910-1927). Como resultados da pesquisa, foi possível observar os modos específicos como os debates legislativos para a assistência psiquiátrica aparecem de modo diferenciado nos dois espaços analisados: a circulação e influência de médicos psiquiatras na dinâmica específica da produção de um registro legislativo no âmbito da Câmara dos Deputados; a existência de continuidades e descontinuidades entre os projetos de lei analisados; a presença constante nos debates de matérias relativas ao federalismo e à hierarquia dos Poderes Executivo, Legislativo e Judiciário na implementação de mudanças na Assistência a Alienados; nas atas da SBNPML e nas notícias dos Anais Brasileiros de Psiquiatria, Neurologia e Medicina Legal observa-se a falta de controvérsias, apesar da presença do tema legislativo nesta sociedade científica.

\section{Apresentação}

O objetivo deste trabalho é analisar os debates em torno da elaboração de documentos legislativos para a área da assistência psiquiátrica no contexto brasileiro da Primeira República,

\footnotetext{
1 Este trabalho integra uma pesquisa financiada pelo CNPq, por meio de uma bolsa de iniciação científica, iniciada em agosto de 2014 e concluída em julho de 2015. Está integrado ao projeto de pesquisa mais amplo da minha orientadora, Prof. ${ }^{a}$ Dr. ${ }^{a}$ Ana Teresa A. Venancio (DEPES/COC/FIOCRUZ) "Atores, ideias, práticas psiquiátricas e construção social da diferença (1903-1970)", assim como o Grupo de Pesquisa do CNPq "O físico, o mental e o moral na história dos saberes médicos e psicológicos", no qual se insere, mais especificamente, na linha de pesquisa "História da psiquiatria e de outros saberes sobre o psíquico: políticas públicas, instituições e terapêuticas".

* Graduado em História pela Universidade do Estado do Rio de Janeiro, atualmente é mestrando do Programa de PósGraduação em História das Ciências e da Saúde da Casa de Oswaldo Cruz (Fiocruz). E-mail: joseroberto_hist@hotmail.com.
} 


\section{artigos}

José Roberto Silvestre Saiol

realizados em dois espaços sociais, a saber: os debates entre parlamentares e as discussões de propostas para a legislação psiquiátrica que circularam na Sociedade Brasileira de Psiquiatria, Neurologia e Medicina Legal, ${ }^{2}$ buscando observar os principais atores sociais envolvidos, suas propostas e argumentos de trabalho.

A relevância desta investigação está justamente na originalidade de seu objeto, tendo em vista que a historiografia sobre a história da psiquiatria no Brasil, majoritariamente circunscrita ao período da segunda metade do século XIX até meados dos anos $1930{ }^{3}$ não tem abordado este tipo de acontecimento histórico que são os debates e a negociação social e política daí decorrente para a produção das versões finais dos documentos legislativos em que diferentes concepções e correntes políticas podem estar postas em jogo. ${ }^{4}$

Neste sentido, o presente texto apresenta o resultado da análise do processo de tramitação dos projetos de decretos voltados para a reorganização da Assistência a Alienados, contidos nos Anais da Câmara dos Deputados, relativos aos anos de 1903 e 1927, e a análise das atas da SBPNML referente ao recorte temporal privilegiado.

Para dar conta desses objetivos, o trabalho se concentrou na busca e análise de dois tipos de fontes primárias, a saber: os debates legislativos registrados nos Anais da Câmara dos Deputados; e

\footnotetext{
2 A Sociedade Brasileira de Neurologia, Psiquiatria e Medicina Legal foi fundada durante uma reunião na Academia de Medicina, no Rio de Janeiro, em 17/11/1907, por um grupo de 40 médicos, dentre os quais destacam-se nomes como os de: Miguel Couto, Juliano Moreira, Fernandes Figueira, Carlos Eiras, Afrânio Peixoto, Miguel Pereira, Carlos Seidl, Ulysses Vianna Filho, Antonio Austregésilo, com o propósito de, segundo seus fundadores, trabalhar em prol da maior difusão do estudo dos "ramos do conhecimento médico" que a nomeavam, assim como "fazer uma grande propaganda em favor da melhora da sorte dos alienados" e daqueles que a eles se dedicavam. Cf. CERQUEIRA (2013).

${ }^{3}$ Ver: VENANCIO \& CASSILIA (2010).

${ }^{4}$ Num primeiro momento, a opção por trabalhar com essas fontes justificou-se por se tratarem de documentos ainda pouco explorados pela historiografia. Além disso, embora cientes das limitações impostas por um trabalho construído apenas a partir deste material, nos restringimos a ele tendo em vista os limites de um projeto de iniciação científica com duração de apenas um ano. Assim, optamos por deixar o trabalho com os periódicos da imprensa leiga para o ano seguinte. Contudo, o tema dos debates legislativos sobre a assistência aos alienados acabou não aparecendo com a frequência que esperávamos nas páginas de alguns dos periódicos de maior circulação da Primeira República, o que nos obrigou a reformular o tema da pesquisa, ampliando-o às representações da Assistência aos Alienados divulgadas pela imprensa leiga da época.
} 


\section{artigos}

\section{O debate legislativo sobre a assistência psiquiátrica na Primeira República}

as atas da Sociedade Brasileira de Psiquiatria, Neurologia e Medicina Legal, as quais se encontram publicadas no periódico da referida instituição ${ }^{5}$.

Para nos auxiliar na operação metodológica destas fontes, lançamos mão de alguns trabalhos. Como mencionamos, privilegiamos aqui a análise dos Anais da Câmara dos Deputados. Encontramos a sugestão para o trabalho com este tipo específico de documentação em Pinsky (2006). Nele, a autora demonstra como este tipo de publicação concede-nos o acesso às discussões dos mais variados projetos legislativos, mesmo as mais polêmicas. Outro trabalho que nos forneceu contribuições relevantes intitula-se "Notas sobre os historiadores e suas fontes", no qual Tânia de Luca discute as diferentes acepções das noções de "documentos" e "fontes históricas", oferecendonos uma distinção bastante precisa em relação a tais noções. Segundo a autora, "documentos" são vestígios do passado independente de seu suporte ou natureza; por outro lado, as "fontes" são o conjunto de documentos mobilizados pelo historiador no decorrer de sua pesquisa. ${ }^{6} \mathrm{O}$ terceiro trabalho é a dissertação de mestrado de Márcia Pazin, onde a autora realiza uma "pesquisa de Tipologia Documental em acervo histórico, utilizando como modelo o caso da Assembleia Legislativa Provincial de São Paulo" (PAZIN, 2005: 05).

Guardando-se os devidos cuidados teórico-metodológicos - afinal, trata-se do estudo de uma instituição diferente da qual estamos debruçados, inclusive em regime político e temporalidade distinta -, acreditamos que Pazin (2005) propõe questões pertinentes que ajudam a nortear o processo de leitura e análise dos Anais da Câmara dos Deputados. Somos incitados pela autora a nos questionarmos acerca do contexto de produção e tramitação da documentação produzida dentro deste espaço social, bem como a observar o que esta documentação revela sobre a estrutura e funcionamento da instituição. Outra contribuição relevante deste trabalho é apresentar um

\footnotetext{
${ }^{5}$ Trata-se dos Arquivos Brasileiros de Psiquiatria, Neurologia e Medicina Legal (ABPNML), que a partir de 1918, passariam a se chamar Arquivos Brasileiros de Neuriatria e Psiquiatria (ABNP).

6 LUCA (2012). p. 19.
} 


\section{artigos}

José Roberto Silvestre Saiol

"Glossário de formatos, espécies e tipos documentais da Assembleia", no qual constam verbetes com as definições dos tipos documentais e o histórico de utilização de cada um dos termos ${ }^{7}$.

Apesar de densa, a documentação consultada não é ampla, devido à impossibilidade de consulta a alguns volumes dos Anais da Câmara dos Deputados disponíveis para pesquisa na Biblioteca da Assembleia Legislativa do Rio de Janeiro. Nesta publicação consta a transcrição de todas as seções legislativas. A princípio acreditávamos que tais documentos nos concederiam acesso às contendas em torno da elaboração das leis para a assistência psiquiátrica - o que de fato é possível observar em relação a outras matérias, tais como a inclusão do divórcio no código civil. Entretanto, no que concerne a documentação levantada, quase não há polêmica ou contenda em relação aos projetos propostos para a assistência psiquiátrica. Se por um lado tal fato frustrou um pouco nossas expectativas, por outro demonstrou que esta oferece informações importantes acerca do processo de elaboração das leis. Além disso, dada a diferença de nomenclaturas existente entre os projetos de $l e i^{8}$ e as leis efetivamente aprovadas, passamos a cotejar o conteúdo dos projetos de lei com o conteúdo das leis publicadas. Finalmente, cabe destacar que privilegiamos a análise da documentação relativa aos debates parlamentares em torno da promulgação dos decretos de reorganização da assistência, e também da concessão de novos regulamentos a ela no período compreendido entre os anos de 1903 e 1927, por considerarmos que se trata de um momento de intensas transformações na assistência a alienados.

O levantamento das atas da Sociedade Brasileira de Psiquiatria, Neurologia e Medicina Legal (SBNPML), relativas ao recorte temporal aqui privilegiado, foi realizado a partir da consulta à dissertação de mestrado de Cerqueira (2014), na qual a autora investiga a atuação da SBNPML no processo de institucionalização da psiquiatria no Rio de Janeiro, por meio das atas da Sociedade entre 1908 e 1933. Tal trabalho disponibiliza referências detalhadas acerca de um amplo conjunto documental, reunidas em uma tabela que está dividida em "atas consultadas" - onde são

\footnotetext{
7 PAZIN (2005). p. 05; 11.

${ }^{8}$ Cf. glossário supracitado, a definição de Projeto de lei diz tratar-se de: proposta escrita de uma norma que deve ser apresentada a uma câmara ou assembleia legislativa para ser discutida e votada, e posteriormente, transformada em lei. PAZIN, op. cit., pp.124.
} 


\section{artigos}

O debate legislativo sobre a assistência psiquiátrica na Primeira República

apresentados detalhadamente o tipo de sessão, a data e o local da reunião - e "referências", onde são apresentadas as coordenadas para a consulta direta às atas publicadas relativas a tais sessões. Após o levantamento, foi realizada a leitura e análise do material encontrado.

\section{Os debates legislativos no interior da Câmara dos Deputados}

Segundo levantamento prévio, o conjunto de leis de reorganização da assistência psiquiátrica ou de concessão de novos regulamentos a ela, compreendidas no período entre 1903 e 1927, é composto de cinco registros legislativos. Entretanto, em minha pesquisa nos volumes disponíveis para consulta dos Anais da Câmara dos Deputados, encontrei referências apenas a debates em torno das questões que vão originar dois destes atos legislativos: o Decreto $n^{\circ} 1132$ de 22/12/ 1903 que reorganiza a assistência a alienados e o Decreto no 5.148-A, de 10 de janeiro de 1927.

\section{II.1. O projeto n. 316 e o projeto n. 303 (1903)}

O primeiro registro analisado aqui é o projeto n³16, de 1903, que "Reorganiza a Assistencia a Alienados (com pareceres das Comissões de Instrucção e Saude Publica, de Constituição, Legislação e Justiça e de Orçamento)", que, depois de finalizado seu processo de tramitação, veio a ser promulgado como Decreto $^{9} \mathrm{n}^{\circ} 1132$, de 22 de dezembro de 1903.

O decreto $n^{\circ} 1132$, que reorganiza a assistência a alienados, sancionado pelo então presidente Rodrigues Alves (1848-1919) e pelo ministro da Justiça e Negócios Interiores (1902-1906) J.J. Seabra (1855-1942), determina o recolhimento a um estabelecimento de alienados os indivíduos que, por moléstia mental, congênita ou adquirida, comprometessem a ordem pública ou a segurança das pessoas. Determina ainda que a reclusão só seria efetiva caso a alienação fosse comprovada. Uma resolução bastante interessante deste registro é que, a partir de então, os enfermos de alienação

\footnotetext{
${ }^{9} \mathrm{Cf}$. glossário supracitado, Decreto é um ato administrativo que pode ser expedido pelos poderes Judiciário, Legislativo, ou Executivo, com força obrigatória, destinado a assegurar ou promover a ordem política, social, jurídica ou administrativa, podendo ainda ter por objetivo regulamentar uma lei, fixar normas administrativas, nomear, promover ou demitir funcionários. PAZIN, op. cit., pp. 113.
} 


\section{artigos}

José Roberto Silvestre Saiol

mental poderiam ser tratados em domicílio, "sempre que Ihe[s] for[em] subministrados os cuidados necessários".

Observamos ainda que, pela primeira vez, um decreto passa a dispor sobre a guarda provisória dos bens dos alienados. Pelo Art. $4^{\circ}$ "salvo o caso de sentença, no qual logo será dada curatela aos alienados, a autoridade policial providenciará, segundo as circunstâncias, sobre a guarda provisória dos bens deste, comunicando imediatamente o fato ao juiz competente, a fim de providenciar como for de direito." Pela primeira vez também, verificamos uma determinação que prevê a possibilidade de solicitação de um novo exame de sanidade ou a denúncia da falta desta formalidade por parte do próprio alienado. Além disso, o decreto proíbe a reclusão de doentes mentais em cadeias públicas ou entre criminosos.

Neste registro legislativo também é possível perceber as exigências a serem preenchidas pelos estabelecimentos destinados ao tratamento das doenças mentais. Pelo artigo 13, tais estabelecimentos deveriam ser dirigidos por profissionais devidamente habilitados e residentes nos respectivos estabelecimentos, funcionar em edifício adequado que possibilite aos alienados a prática de exercícios ao ar livre, possuir seções em que estejam devidamente separados os doentes mentais por sexo e pela natureza da moléstia mental. Pudemos verificar também que novas especialidades profissionais foram integradas ao pessoal da Assistência aos Alienados no Distrito Federal, a saber: médicos alienistas, um pediatra, um médico para o pavilhão de doenças infecciosas e um chefe dos serviços Kinesotherapicos ${ }^{10}$. Prevê também a punição dos infratores desta lei com penas de prisão e multa.

A determinação que mais salta aos olhos é a instituição de uma Comissão de Inspeção composta por um procurador da república, um curador de órfãos e de um profissional de reconhecida competência responsável pela fiscalização de todos os estabelecimentos de alienados, públicos e particulares existentes no país. Esta determinação se parece bastante com aquela do Decreto $n^{\circ} 10244 / 1889$ que previa a nomeação das comissões que julga convenientes para a

\footnotetext{
${ }^{10}$ Ao que parece, a grafia atual do termo seria "cinesioterápicos". Segundo o Dicionário Priberam, "Cinesioterapia" é um tratamento feito através da realização de movimentos do corpo, ativos ou passivos.
} 


\section{artigos}

\section{O debate legislativo sobre a assistência psiquiátrica na Primeira República}

fiscalização e melhoramento do serviço da Assistência. Em 1903, entretanto, devido às circunstâncias de sua promulgação, ela me parece possuir um caráter permanente e regulamentado. O registro legislativo de 1889, por outro lado, tem sua definição e ação um pouco vagas, informando unicamente no terceiro item do artigo segundo que, ao Conselho de Assistência ${ }^{11}$ era permitida a nomeação das comissões, tal como mencionado acima. Mas o dito item não discorre sobre sua composição e suas competências, tal como ocorre no Decreto nº 1132.

Seguindo Azevedo (2012), o Relatório da Comissão de Inquérito que investigou o escândalo de $1902^{12}$ propôs a criação das comissões de inspeção permanentes cujo dever seria o de inspecionar regularmente as instituições asilares para alienados e avaliar seu estado em relatórios que seriam enviados ao Ministro dos Negócios Interiores todos os anos. Para o autor, isto representava uma tentativa do governo republicano de controlar e regular a prática alienista no Brasil (Azevedo, 2012: $11 ;$ 16). Isto se reflete na legislação, na medida em que, por exemplo, o decreto de 1903 já mencionado prevê que, em caso de criação e reforma de alguma instituição destinada ao tratamento de alienados, tal comissão deveria emitir um parecer sobre o projeto. Além disso, os diretores destes estabelecimentos deveriam enviar mensalmente uma relação com o nome dos enfermos internados no mês anterior.

O projeto de lei que dá origem ao referido decreto é mencionado em oito sessões da Câmara

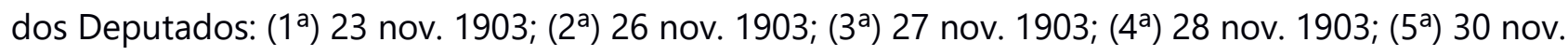

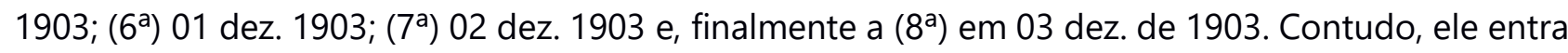

\footnotetext{
11 Em meu relatório final (expediente 2013-2014), propus a hipótese de que, apesar de instituído sob o regime imperial (1889), o Conselho de Assistência para a Casa do São José, Colônia de São Bento e Asilo do Conde de Mesquita constituiria uma espécie de "embrião" do que no ano seguinte, no contexto da república, viria a ser a Assistência Médica e Legal de Alienados.

12 O escândalo de 1902, constantemente reiterado pela historiografia e detalhadamente estudado por Azevedo (2012), diz respeito a um grande desfalque ocorrido nas contas do Hospício Nacional de Alienados da capital federal que tomou conta das páginas dos jornais diários naquele ano. Sua grande repercussão resultou na mobilização imediata do governo central num esforço de investigação encarnado na figura de uma comissão de inquérito que, após a apresentação de seus relatórios, daria origem às comissões de inspeção implementadas pela lei n. 1132 de 1903, que reorganizava a Assistência aos Alienados.
} 


\section{artigos}

José Roberto Silvestre Saiol

na pauta de debates em apenas três delas, a saber: na $1^{\mathrm{a}}$, na $5^{\mathrm{a}}$ e na $8^{\mathrm{a}}$ - entre as quais o material mais farto encontra-se disponível na $1^{a}$ sessão.

A 23 de novembro de 1903 tem lugar na Câmara dos Deputados a 138a Sessão, na qual estava presente João Carlos Teixeira Brandão (1854-1921) ${ }^{13}$, relator da Comissão de Instrucção e Saude Publica (CISP) cujo parecer ${ }^{14}$ acompanha o projeto de lei $n^{\circ} 316 / 1903$. Posto em discussão o referido projeto, são apresentados os pareceres das três citadas comissões.

O primeiro parecer submetido à apreciação da Câmara dos Deputados, datado de 31 de agosto de 1903, é o da Comissão de Instrucção e Saúde Pública, elaborado a partir das considerações dirigidas à dita comissão pelo presidente da república, à época Rodrigues Alves, para a "decretação das providencias necessarias para que possa ser reorganizada a Assistencia a Alienados e levados a effeito os melhoramentos materiaes que são de mister para a boa execução do mesmo serviço" ${ }^{15}$.

Antes, contudo, de propor tais melhoramentos, a comissão levantou uma "questão preliminar", a qual estaria provocando controvérsias: "é da competência da União prover a manutenção do tratamento dos alienados no Districto Federal ou em qualquer dos Estados da União?" ${ }^{16}$. A resposta da comissão a esta pergunta é negativa, com a ressalva de que, desde a proclamação da república, esta era a situação no Distrito Federal, "facto é esse explicável mais por circumstancias [sic.] especiaes, inherentes á natureza do serviço e ás suas relações de dependências de outros, municipios,administrados pela União, do que por qualquer outro motivo"17. Segundo a comissão, seria o desconhecimento destas "circunstâncias especiais" - as quais não são claramente explicadas

\footnotetext{
13 "Em abril de 1883, após concurso no qual obteve o primeiro lugar, foi nomeado lente da cadeira de clínica psiquiátrica e de moléstias nervosas da Faculdade de Medicina do Rio de Janeiro, a qual havia sido introduzida nesta instituição naquele mesmo ano. [...] Foi nomeado, em 24 de outubro de 1884, facultativo clínico do Hospício de Pedro II, e em 27 de fevereiro de 1887 tornou-se diretor do serviço sanitário deste estabelecimento, substituindo Agostinho José de Souza Lima . [...] Em 18 de fevereiro de 1890 foi nomeado diretor geral da Assistência Médico Legal de Alienados, e em 27 de fevereiro de 1897 tornou-se inspetor geral de Assistência a Alienados, ocupando este cargo até 1899". [...] - João Carlos Teixeira Brandão. Dicionário Histórico-Biográfico das Ciências da Saúde no Brasil (1832-1930). Capturado em 07 ago. 2014. Disponível em: <http://www.dichistoriasaude.coc. fiocruz.br/iah/pt/verbetes/branjcteix.htm>.

${ }^{14} \mathrm{Cf}$. glossário supracitado, Parecer é uma opinião técnica ou científica sobre um ato, servindo de base para a tomada de decisão. PAZIN, op. cit., pp. 152.

${ }^{15}$ Anais da Câmara dos Deputados, doravante ACD, Nov. 1903, pp. 804.

${ }^{16}$ ACD, Nov. 1903, pp. 805.

17 Idem.
} 


\section{artigos}

\section{O debate legislativo sobre a assistência psiquiátrica na Primeira República}

- que estaria determinando a "má vontade" no Corpo Legislativo contra aquela instituição, expressa "ora na recusa dos meios orçamentarios solicitados, ora em projectos de lei, destinados a fazer reverter, para as instituições de caridade a administração da Assistencia a Alienados." ${ }^{18}$

Para a comissão, isso esconderia a questão principal de vista: se, por um lado o afastamento do alienado do convívio social promovido pela autoridade pública garantiria a tranquilidade social, por outro, constituiria uma violação de um direito do alienado, o que demandaria, por parte do poder público, uma reparação. Em outras palavras, tal violação, apesar de legítima - pois visa a tranquilidade social - deveria ser suavizada garantindo ao alienado o bem-estar compatível com a sua "situação moral".

Ainda segundo a comissão, tanto no Distrito Federal quanto nos estados da União, a reclusão dos alienados seria um encargo das autoridades responsáveis pela garantia da ordem pública, e às autoridades judiciárias caberia o dever de zelar pelos seus direitos, tarefa impossibilitada pela falta de uma legislação específica sobre o assunto. Esta falta justificaria a intervenção dos governos na administração dos asilos. No Distrito Federal, tal "anomalia" seria agravada pela subordinação da polícia ao Executivo. Com esta hierarquia, o Executivo acabava interferindo na administração de "um serviço meramente local" ${ }^{19}$. Para a comissão, o serviço da assistência dependeria de uma "aprendizagem gradual e progressiva, inconciliável, portanto, com as surprezas administrativas que as contingencias políticas geram" ${ }^{20}$. Parece-me, portanto, que na ordem do dia, o que estava em jogo era a questão da hierarquia entre as diferentes instâncias governamentais em relação ao serviço da assistência psiquiátrica.

O tom da narrativa, que constantemente remete ao "estado de ruína e de descrédito" da Assistência a Alienados, parece se referir ao já mencionado escândalo de 1902. Neste sentido, o parecer da "Comissão de Instrucção e Saude Publica" (CISP) é elaborado em cima de comparações feitas entre o relatório da Comissão de Inquérito que investigou o dito escândalo, e o daquela

\footnotetext{
18 Idem.

19 Idem.

20 Idem.
} 


\section{artigos}

José Roberto Silvestre Saiol

nomeada em 1896, época em que, segundo a CISP, a situação da assistência era digna de "encômios"21. Possivelmente, é este relatório de 1896 que dá origem ao Decreto n².467, de 19 fev. 1897, que "dá novo regulamento para a Assistencia Medico-legal a Alienados".

Parece-me ainda que os problemas identificados pela CISP em 1903 estão no regulamento de 1899 (Decreto n 3.244 de 29 mar. 1899). Entre eles, estariam: (1º) a atribuição a um único funcionário de tarefas que, nos regulamentos anteriores, eram realizadas por vários. Exemplo disso é que no regulamento de 1897 era conferida a um médico específico a direção do museu anatomopatológico, disposição alterada no regulamento de 1899, que passou a atribuir ao diretor do Hospício esta função; $\left(2^{\circ}\right)$ a supressão de "lugares técnicos" teria estabelecido no serviço deficiências insanáveis. Observando as tabelas com os vencimentos dos funcionários da Assistência a Alienados, contidas nos regulamentos de 1897 e 1899, verificamos neste último a supressão de funções como a de contador, ajudante de farmacêutico e oftalmologista. Muito mais amplo é o quadro de funcionários anexo ao decreto 1.132 de 1903, que conta, apenas no Hospício Nacional, com 22 funções, contra 10 do regulamento de 1899 e 14 do regulamento de 1897; (3º) a falta da exigência de especialização para o cargo de diretor [tanto da Assistência a Alienados quanto dos asilos a ela subordinados, me parece], o que teria colocado "a testa dessa instituição" indivíduos sem especialização e "incapazes de a estudar e muito menos de a comprehender"22. O regulamento de 1897 confere "a superintendência administrativa e scientifica de todos os estabelecimentos da Assistencia" a um médico "competente em psychiatria"23. O regulamento de 1899, por sua vez, além de suprimir o cargo de diretor da Assistência como já mencionado, e atribuir a superintendência do serviço ao diretor do Hospício Nacional, exige apenas que o cargo seja ocupado por um médico; $\left(4^{\circ}\right)$ a acumulação de doentes no hospício - tema vastamente explorado pela literatura especializada que, de acordo com o parecer da CISP, prejudicaria a separação dos doentes mentais e, consequentemente, o seu tratamento.

\footnotetext{
${ }^{21}$ Elogios.

${ }^{22}$ ACD, Nov. 1903, pp. 805-806.

23 Decreto n. 2.467 de 19 fev. 1897, pp. 01.
} 


\title{
artigos
}

\section{O debate legislativo sobre a assistência psiquiátrica na Primeira República}

Mais interessante ainda é a insistência da CISP na criação de uma lei que visasse à regularização da situação dos alienados, entendidos a partir de então como sujeitos de direito. Neste sentido, a narrativa do parecer discorre, principalmente, sobre os possíveis abusos ou "sequestros" sofridos pelos doentes mentais, especialmente em asilos e casas de saúde privadas - classificadas pelo parecer como "estabelecimentos industriais" 24 -, recorrendo-se ao exemplo de experiências internacionais - são citados os casos da Bélgica, da França, da Itália e da Inglaterra ${ }^{25}$ - para evidenciar a necessidade de uma legislação capaz de salvaguardar os direitos dos alienados; garantia esta que, mesmo alcançada nos países mencionados, não extinguiu completamente os casos de violação destes direitos.

Outra questão levantada pelo parecer da CISP é a da entrada e saída de pessoas das instituições asilares. Para esta comissão,

\begin{abstract}
a Assistencia é destinada ao tratamento e á reclusão dos alienados, em estado agudo da molestia, ainda curáveis; e á reclusão, unicamente, dos que, apezar de incuráveis, continuem agitados e por essa circumstancia não possam permanecer em liberdade ou no seio das famílias. É até por esse caráter que a Assistencia se distingue dos estabelecimentos de caridade. ${ }^{26}$
\end{abstract}

Cabe notar que esta determinação exclui do público alvo das instituições asilares não apenas os inválidos ou mendigos remetidos pela polícia, mas também os "dementes inofensivos".

O último ponto levantado pela comissão diz respeito aos encargos relativos à internação de doentes mentais estrangeiros. Se, à época, tal despesa estava a cargo do poder público, para os membros da CISP era necessário que o Brasil, seguindo a tendência adotada por outros países, procedesse imediatamente após a internação do doente mental com o pedido de repatriação do

\footnotetext{
${ }^{24}$ ACD, Nov. 1903, pp. 806.

${ }^{25}$ Apesar de reconhecer a importância da análise comparativa com esta legislação internacional, não foi possível realiza-la nos limites deste trabalho.

${ }^{26}$ ACD, Nov. 1903, pp. 807.
} 


\section{artigos}

José Roberto Silvestre Saiol

mesmo, bem como com a solicitação de uma indenização pelas despesas feitas e fazer com o alienado.

As matérias a serem consideradas, portanto, na elaboração de tal lei seriam de ordem profissional, sobretudo na demanda por funcionários devidamente habilitados para o tratamento a alienados, da ordem dos procedimentos de entrada e saída dos alienados e do seu tempo de permanência em instituições asilares e, finalmente, da ordem da garantia dos direitos dos alienados. A CISP conclui o parecer indicando que este seja levado à Comissão de Constituição, Legislação e Justiça, para que seja formulado um projeto de lei que leve em consideração a garantia da liberdade individual e da gestão dos bens dos alienados. Assinam o parecer: o presidente interino, Malaquias Gonçalves²7, o já citado relator, Teixeira Brandão, Satyro Dias (1844-1913), Valois de Castro (18551939), Germano Hasslocher (1862-1911) e Sá Freire (1870-1947).

A sessão da Câmara dos Deputados tem continuidade com a leitura do parecer da Comissão de Constituição, Legislação e Justiça (CCLJ). Nele, a dita comissão informa que considera a matéria de direito civil e penal e, portanto, da competência do Congresso Nacional legislar sobre a reclusão de alienados e a administração de seus bens tanto no distrito federal quanto nos estados da União. O parecer versa, portanto, sobre o processo e as formalidades de internação dos doentes mentais e a assistência a eles devida, sobre os requisitos de funcionamento das instituições asilares, atribuindo à União a superintendência do serviço "em tudo quanto interesse á pessoa e á fortuna dos alienados contra as possíveis explorações de seu infortúnio"28 e, finalmente, organiza o serviço no Distrito Federal.

A redação do texto do projeto de lei apresentado pela $C C L$ é a mesma do Decreto n. ${ }^{\circ}$ 1.132/1903, já apresentado aqui. Assinam o parecer na Sala das Comissões, a 08 de outubro de 190[3]: o presidente Paranhos Montenegro, Ângela [sic.] Pinheiro, Frederico Borges, Teixeira de Sá (1835-1920) e Hossannah de Oliveira. Anexa ao parecer, segue a "Tabella de vencimentos do pessoal

\footnotetext{
${ }^{27}$ Os personagens citados sem referências sobre nascimento e morte assim o foram por conta da ausência de informações a este respeito.

${ }^{28}$ ACD, Nov. 1903, pp. 808.
} 


\section{artigos}

\section{O debate legislativo sobre a assistência psiquiátrica na Primeira República}

da Assistência aos Alienados", cuja redação é a mesma do decreto efetivamente aprovado. Além dos nomes acima citados, assina também a dita tabela o relator Luiz Domingues (1860-1922).

Na continuidade da sessão, verifica-se a leitura do parecer da Comissão de Orçamento. Tal parecer reforça o coro dos demais, reconhecendo a necessidade de reorganização da Assistência, sobretudo por conta de uma visita realizada ao Hospício Nacional na companhia do Ministro J.J. Seabra, reafirmando os prejuízos causados ao serviço por conta da deficiência de pessoal, das condições "deploráveis" dos edifícios e da superlotação. A dita comissão declara ainda sustentar o parecer da CCL, propondo, contudo, algumas alterações na tabela de vencimentos apresentada "afim de estabelecer-se a uniformidade" ${ }^{29}$. Na prática, tais alterações propõem uma série de reduções nos valores dos vencimentos de alguns cargos, como por exemplo no de médico alienista, cujo vencimento na tabela do projeto da CCL é de 6:000\$000, e que na tabela proposta pela Comissão de Orçamento cairia para 4:800\$. Nenhuma destas alterações, entretanto, verificam-se no texto final aprovado na forma do decreto $n^{\circ} 1.132$, tendo elas sido revogadas em votação durante a segunda discussão do projeto, em sessão de 30 de novembro de 1903.

Outra sugestão de alteração no texto do projeto de lei, proposta pela Comissão de Orçamentos que não foi contemplada no texto final da lei, referente ao seu art. 12 , sugere que a comissão de inspeção seja composta por um procurador da república, um curador de órfãos e pelo diretor do Hospício Nacional (em substituição ao profissional de reconhecida competência como consta no texto publicado). Assinam o parecer o presidente Cassiano do Nascimento (1856-1912), o relator Laurindo Pitta, Urbano Santos (1859-1922), David Campista (1863-1911), Francisco Veiga e Anizio de Abreu, em data de 23 de novembro de 1903. A este parecer, opõe-se um voto em separado ${ }^{30}$ assinado em 09 de novembro de 1903, pelo relator Cornelio da Fonseca (1894-1908) ${ }^{31}$. Este informa que seu parecer leva em conta apenas a tabela dos vencimentos apresentada no projeto de lei

\footnotetext{
${ }^{29}$ ACD, Nov. 1903, pp. 810.

30 Voto alternativo de parlamentar ao do relator de determinada matéria. Ocorre quando o autor do voto em separado diverge do parecer dado pelo relator. Ver destaque para votação em separado. Definição obtida no website do Senado Federal. Disponível em: <http://www12.senado.leg.br/noticias /glossario-legislativo/voto-em-separado>

31 http://cpdoc.fgv.br/dicionario-primeira-republica/4
} 


\section{artigos}

José Roberto Silvestre Saiol

proposto pela CCLJ. Verificamos que a determinação deste voto em separado acaba sendo mantida na redação do texto final do decreto $n^{\circ} 1.132$.

A sessão tem continuidade com a leitura da "Mensagem e Exposição de Motivos a que se Referem os Pareceres Supra". A primeira mensagem é do presidente Rodrigues Alves, dirigida ao Congresso Nacional em 03 de agosto de 1903, e que solicita, por parte daquela casa, a decretação das providências necessárias para a reorganização da Assistência a Alienados, bem como a realização dos melhoramentos materiais necessários para a boa execução do serviço. Tal mensagem tem origem em outra, dirigida pelo Ministro J.J. Seabra ao presidente Rodrigues Alves, solicitando exatamente que este último envie ao Congresso Nacional um pedido de reorganização da assistência a alienados, bem como dos já mencionados melhoramentos materiais necessários.

O que é interessante na mensagem do ministro J.J. Seabra é que ela é quase completamente composta pelo texto de um ofício dirigido a ele pelo diretor do Hospício Nacional à época, Juliano Moreira $^{32}$. E é a partir das demandas apresentadas neste ofício, bem como também daquelas apresentadas no relatório da Comissão de Inquérito nomeada para investigar o escândalo de 1902 que o projeto de lei é construído. Podemos verificar neles, portanto, a solicitação de aumento das verbas, do número e da variedade de profissionais e especialistas contratados para o trabalho no serviço da assistência e, ainda, uma espécie de orçamento em que constam as reformas necessárias tanto no Hospício Nacional quanto nas colônias de alienados, cujo valor total da despesa estimavase em 729:130\$. É este planejamento de orçamento que dará origem a outro projeto de lei, o projeto

\footnotetext{
32 "Juliano Moreira (1873-1933), baiano de Salvador, é frequentemente designado como fundador da disciplina psiquiátrica no Brasil. [...] De 1903 a 1930, no Rio de Janeiro, dirigiu o Hospício Nacional de Alienados. Neste, embora não fosse professor da Faculdade de Medicina do Rio, recebia internos para o ensino de psiquiatria. Aglutinou ao seu redor médicos que viriam a ser, eles também, organizadores ou fundadores na medicina brasileira, de diversas especialidades: neurologia, psiquiatria, clínica médica, patologia clínica, anatomia patológica, pediatria e medicina legal, tais como Afrânio Peixoto, Antonio Austragésilo, Franco da Rocha, Ulisses Viana, Henrique Roxo, Fernandes Figueira, Miguel Pereira, Gustavo Riedel e Heitor Carrilho, entre outros. [...] Como ele mesmo descreveu, foram estas as mudanças: instalação de laboratórios de anatomia patológica e de bioquímica no hospital; remodelação do corpo clínico, com entrada de psiquiatras/neurologistas e outros especialistas (de clínica médica, pediatria, oftalmologia, ginecologia e odontologia); a abolição do uso de coletes e camisas de força; a retirada de grades de ferro das janelas; a preocupação com a formação dos enfermeiros; o grande cuidado com os registros administrativos, estatísticos e clínicos, entre outros. Sua atuação institucional incluiu a organização da "Assistência aos Alienados", mais tarde Serviço Nacional de Assistência aos Psicopatas, tendo redigido, em 1903, uma proposta de reforma do Hospício Nacional e insistido junto ao governo para a aprovação da legislação federal de assistência aos alienados, promulgada em 22/12/1903". Consultado em: ODA \& DALGALARRONDO (2000: p. 178-179).
} 


\section{artigos}

O debate legislativo sobre a assistência psiquiátrica na Primeira República

n. 303/1903, que autoriza o Governo "a abrir ao Ministério da Justiça e Negócios Interiores o crédito de 729:130\$, suplementar a verba Obras [...] para as instalações, reparos e outras despesas com o Hospício e as Colônias de Alienados" ${ }^{33}$. Tal projeto acaba aprovado em votação e enviado à Comissão de Redação na mesma sessão, em 03 de dezembro de 1903, quando é aprovado o projeto de reorganização da assistência, ambos em $3^{a}$ discussão - o mínimo necessário, segundo Márcia Pazin ${ }^{34}$. Após a leitura do projeto $n^{\circ} 303$, o presidente da sessão anunciou a ordem do dia seguinte e ela foi encerrada às $16 \mathrm{~h} 30 \mathrm{~min}$.

O ano de 1903 parece ter inaugurado, portanto, uma série de transformações na assistência psiquiátrica, pelo menos no que concerne ao plano das propostas legislativas. Existe uma breve contenda levantada durante a terceira discussão do projeto n. ${ }^{\circ} 316$, no dia 03 dez. 1903, acerca de um erro numa soma de valores contidos numa das tabelas de vencimentos. O tom desta contenda parece evidenciar, por um lado, uma certa urgência na promulgação da lei de reorganização do serviço da assistência - principalmente se levarmos em conta a velocidade da tramitação e sua aprovação no apagar das luzes do ano de 1903 - e, por outro, a existência de um grupo bastante minoritário "acusado" de tentar obstruir o processo de tramitação da lei, embora as demais fontes consultadas não permitam verificar tal hipótese.

\section{II.2. O projeto $\mathrm{n}^{\circ} 295$ e o projeto $218-\mathrm{A}(1926)$}

Em relação ao ano 1926, onde procurávamos informações acerca da tramitação do projeto que deu origem ao Decreto $n^{\circ}$ 5.148-A, encontramos no volume 10 dos Anais apenas uma nota sobre a então denominada Sociedade Brasileira de Neurologia, Psiquiatria e Ciências Afins ${ }^{35}$ (SBNPCA). Em sessão de 01 de outubro de 1926, foi aprovado, com substitutivo, o projeto n 295/1926, que declara de utilidade pública a Sociedade Brasileira de Neurologia e Psiquiatria e o "Ermitage" de Petrópolis ${ }^{36}$.

\footnotetext{
33 ACD, Dez. 1903, pp. 63.

34 PAZIN, op. cit., pp. 46.

35 Ver nota 2.

${ }^{36}$ Conforme define o parecer da Comissão de Justiça, o "Ermitage" seria estabelecimento hospitalar, sistema de pavilhões isolados para convalescentes de todas as enfermidades, e, à época, alvo das mais elogiosas referências tanto pela Sociedade de Medicina e Cirurgia do Rio de Janeiro, quanto por vários cientistas. Cf. ACD, Out. 1926, pp. 20.
} 


\section{artigos}

José Roberto Silvestre Saiol

Tal projeto teria origem em outro, de $n^{\circ} 73 / 1925$, proposto por Antonio Austregésilo ${ }^{37}$, e que solicitava que a SBNPCA fosse assim declarada. Assinam o parecer da Comissão de Justiça, em 30 de setembro de 1926, o presidente Manoel Villaboim (1867-1937), o relator Horacio Magalhães, Getulio Vargas (1882-1954), João Elysio, Annibal B. Toledo, Rego Barros, Raul Machado e José Gonçalves.

O volume 12, por sua vez, contém, em sessão de 22 de outubro de 1926, os pareceres das comissões de saúde e finanças acerca do projeto de lei $n^{\circ} 218-A$ que, a princípio, reorganiza a Assistência a Psicopatas, alienados ou não, no distrito federal e nos estados. É este projeto de lei que dá origem ao Decreto $\mathrm{n}^{\circ}$ 5.148-A, de 10 de janeiro de 1927, sancionado pelo presidente Washington Luis (1869-1957) e pelo Ministro da Justiça e Negócios Interiores Augusto de Vianna do Castello (1874-1953), que reorganiza a Assistência a Psicopatas no Distrito Federal.

Segundo o parecer da Comissão de Saúde, o projeto de reforma da lei de assistência a psicopatas teria sido apresentado pelo deputado Afrânio Peixoto ${ }^{38}$. O texto faz referência à reforma de 1903 e à atuação de Juliano Moreira a época, mas aponta que a evolução da matéria e a "míngua" dos recursos oficiais acabaram resultando na estagnação e no retrocesso do serviço da assistência psiquiátrica. Destaca ainda que a lei que rege a dita matéria estaria fora dos moldes modernos - da profilaxia mental -, o que demandava novas bases legais para o funcionamento regular do serviço. Aponta ainda para a necessidade de remunerar adequadamente o pessoal da Assistência a Psicopatas, bem como a de instalações adequadas ao serviço, declarando, portanto, que a reforma na lei da assistência seria urgente.

É interessante notar como a argumentação do parecer atrela à situação das instituições asilares a questão do progresso e da civilização culta e próspera, oferecendo, sempre que possível, exemplos de experiências bem-sucedidas no exterior, sobretudo na Europa. Assinam o parecer, em 13 de

\footnotetext{
37 "O Professor Antonio Austregésilo foi o pioneiro da neurologia brasileira, criando a primeira escola neurológica no Rio de Janeiro em 1912. Ele foi também o primeiro a estudar os distúrbios do movimento no Brasil, tendo publicado vários artigos nesta área, particularmente nas consagradas revistas Revue Neurologique e L'Encephale, incluindo a descrição de um sinal sucedâneo de Babinski e a primeira descrição mundial de distonia pós-traumática". In: TEIVE et al (1999: p. 898). 38 "Afrânio Peixoto (Júlio A. P.), médico legista, político, professor, crítico, ensaísta, romancista, historiador literário, nasceu em Lençóis, nas Lavras Diamantinas, BA, em 17 de dezembro de 1876, e faleceu no Rio de Janeiro, RJ, em 12 de janeiro de 1947". Disponível em: http://www.academia.org.br/abl /cgi/cgilua.exe/sys/start.htm?infoid=44\&sid=127.
} 


\section{artigos}

\section{O debate legislativo sobre a assistência psiquiátrica na Primeira República}

setembro de 1926, o presidente Zoroastro Alvarenga, o relator Antonio Austregésilo, Clementino Fraga (1880-1971), Freitas Merlo, Galdino Filho (1879-1961), José Lino e Berbet de Castro (18941966).

Na continuidade da sessão, tem lugar a leitura do parecer da Comissão de Finanças que, na esteira dos demais vistos até aqui, reforça a necessidade da completa remodelação da assistência psiquiátrica, mencionando inclusive as reclamações dos "mais ilustres psiquiatras" que habitualmente eram deixadas no esquecimento. É aos esforços de Afrânio Peixoto que o parecer atribui a chegada da matéria à Câmara dos Deputados. Desta forma, a comissão emite um parecer favorável à aprovação do projeto n²18-A/1926, levantando ainda a necessidade de melhoramentos nas instalações do Hospício Nacional e dos Asilos Colônias.

Em consonância com o parecer anterior, a Comissão de Finanças atrela a dimensão retrógrada da assistência ao estilo arquitetônico de alguns de seus prédios, "velhas casernas", cuja reformulação era necessária, uma vez que seu aspecto seria incompatível com a evolução da matéria, fazendo referência, inclusive, a experiências estrangeiras como a do "open door" inglês e a grande reforma do hospício "Las Mercedes", na Argentina, e mesmo à experiência de São Paulo com a colônia para alienados de Juquery.

Tudo isso é incompatível com a evolução feliz que se tem operado nos tempos modernos, determinando a supressão de todo meio de contenção mecânica, substituída pelos calmantes do sistema nervoso, pelo isolamento passageiro e pela vigilância permanente feita por enfermeiros educados para esse fim especial, em um gabinete de calma e tranquilidade que se consegue nos asilos modernos, graças aos novos sistemas de tratamentos humanitários e científicos, que fez compreender que, não só o enclausuramento ao qual estavam sujeitos os doentes mentais era desnecessário, mas lhe era prejudicial ${ }^{39}$.

\footnotetext{
${ }^{39}$ ACD, Out. 1926, pp. 297.
} 


\section{artigos}

José Roberto Silvestre Saiol

Neste sentido, a Comissão de Finanças propõe alguns acréscimos ao projeto para que ele inclua transformações nos edifícios e asilos da Assistência, estendendo a eles o projeto de renovação do serviço da Assistência Psiquiátrica. São eles: $\left(1^{\circ}\right)$ o art. 23, que autoriza o governo a "despender até a quantia de dois mil contos de réis para a remodelação do Hospício Nacional e aumento dos pavilhões dos asilos-colônias de alienados, por conta da verba especial destinada na Receita Geral da República à assistência hospitalar ${ }^{\prime \prime 4} ;\left(2^{\circ}\right)$ o art. 24, que inclui o diretor geral da assistência a psicopatas no conselho administrativo da Assistência Hospitalar do Brasil. No entanto, ambos os complementos são vetados.

Só podemos conhecer a razão do veto no caso do primeiro complemento. Uma mensagem do presidente Washington Luis (datada de 10 de janeiro de 1927), lida em sessão de 20 de maio de $1927^{41}$, explica as razões de seu veto a dois artigos do projeto de lei, entre eles, o art. 23 - mas que, no projeto que chegou às suas mãos, constava como art. 25. De acordo com o presidente, a lei de reorganização da Assistência a Psicopatas não poderia, tal como pretendia o projeto, dispor de uma parte considerável dos recursos da verba de assistência hospitalar, uma vez que isso iria contra as disposições da lei orçamentária de 1925 (lei n 4.984 de 31 de dezembro de 1925), cuja aplicação das verbas não poderia ser alterada por uma lei especial, uma vez que tais recursos teriam como finalidade "fazer face às despesas com a manutenção e desenvolvimento da assistência hospitalar no Brasil". 42

O art. 9, por sua vez, que atribui ao Ministro da Justiça e Negócios Interiores a suprema inspeção de todos os estabelecimentos públicos ou particulares destinados ao tratamento de psicopatas, representado por comissões de inspeção formadas em todos os estados da União. $O$ argumento mobilizado por Washington Luiz para o veto é o de que, uma atribuição como esta colidiria com as prerrogativas que a Constituição assegurava aos estados, esbarrando assim na questão do federalismo, crucial à época.

\footnotetext{
${ }^{40}$ ACD, Out. 1926, pp. 298.

${ }^{41}$ ACD, Mai. 1927, pp. 230.

${ }^{42}$ ACD, Mai. 1927, pp. 231.
} 


\section{artigos}

O debate legislativo sobre a assistência psiquiátrica na Primeira República

De volta ao projeto n 218-A/1926, e mais precisamente ao parecer da Comissão de Finanças, verificamos que existem, entre a Tabela de Vencimentos do projeto e do decreto efetivamente aprovado (5.148-A/1927) diferenças nas quantias descritas. Suas ementas, tal como o leitor deve se lembrar, também são distintas e apresentam ainda pequenas alterações no texto do projeto de lei, que se verificam promulgadas no decreto de reorganização. Assinam o parecer o presidente Júlio Prestes (1882-1946), o relator Nabuco de Gouvea, José Bonifácio (1904-1926), Gilberto Amado (1887-1969), Oliveira Botelho (1868-1943), Bianor de Medeiros, Camillo Prates, Homero Pires, Wanderley Pinho (1890-????), Manoel Duarte (1877-1944), Prado Lopes e Salles Junior.

O que se pode inferir disso é que, diferentemente do projeto de reforma de 1903, o processo de tramitação desta lei contou, em certo sentido, com um número maior de intervenções até a produção final do texto enviado para a publicação. Contudo, a impossibilidade de consultar os demais volumes dos Anais da Câmara dos Deputados ${ }^{43}$ acabou barrando nosso acesso a tais intervenções. Cabe destacar ainda que a reforma na lei de assistência psiquiátrica de 1927 marca uma espécie de mudança no paradigma da gestão e tratamento da doença mental no país, mudança esta inserida no contexto da profilaxia mental, campo no qual ainda precisamos aprofundar nossos estudos para oferecermos mais informações relevantes.

\section{As atas da Sociedade Brasileira de Neurologia, Psiquiatria e Medicina Legal}

As atas da SBNPML eram publicadas no interior dos Arquivos Brasileiros de Psiquiatria, Neurologia e Medicina Legal (ABPNML), que a partir de 1918 passariam a se chamar Arquivos Brasileiros de Neuriatria e Psiquiatria (ABNP), periódico criado em 1905 pelo então diretor da Assistência a Alienados, Juliano Moreira, tendo se tornado o órgão oficial de divulgação da SBNPML a partir de 1907, ano de sua fundação ${ }^{44}$. Um aspecto cuja consideração é indispensável no processo de análise desta documentação são as condições materiais de produção e publicação dos Anais. Isso implica diretamente na forma como as atas se apresentam: resumos das sessões, nos quais,

\footnotetext{
43 Estão indisponíveis para consulta - ou por conta de sua inexistência, ou de seu estado de conservação precário - os volumes 11, 13,14, 15, 16, 17, 18, 19 e 20 do ano de 1926.

${ }^{44}$ Cf. CERQUEIRA, op. cit., p. 28.
} 


\section{artigos}

José Roberto Silvestre Saiol

inevitavelmente, perdem-se detalhes das comunicações e dos debates entre os membros. Segundo Cerqueira (2014), o tamanho de cada uma das seções do periódico varia frequentemente de um número para o outro, de acordo com o espaço e os recursos disponíveis para sua impressão. Consequentemente, os resumos e matérias prioritárias tratadas nas atas também variam. Cerqueira levanta, inclusive, a hipótese de um possível processo de editoração das atas, para sua adequação ao espaço disponível na revista ${ }^{45}$.

A análise das atas da SBNPML revelou que o assunto prioritário mais recorrente nas reuniões era a apresentação de casos clínicos. Essa opção possivelmente está ligada à hipótese levantada por Cerqueira (2014) de que haveria, na Sociedade, uma orientação para a formação de um novo perfil profissional de médicos alienistas, cuja atuação não deveria se restringir apenas aos cuidados médicos, mas também incluir o desenvolvimento de pesquisas científicas acerca da matéria psiquiátrica ${ }^{46}$. Os demais temas eram tratados com uma frequência significativamente menor, e diziam respeito à organização interna da própria SBNPML (eleições, associação de novos membros, etc.), impressões de viagens a instituições psiquiátricas de outros estados ou países, solenidades, entre outros.

Contudo, no que diz respeito à temática das propostas legislativas para a Assistência a Alienados, as atas no recorte consultado ofereceram apenas uma ocorrência, que diz respeito, na verdade, não à assistência psiquiátrica, mas sim ao exercício das perícias médico-legais no interior dos tribunais. Já nas edições não consultadas no decorrer desta pesquisa, tomamos conhecimento, por meio do trabalho de Cerqueira (2014.), de algumas ocorrências do tema da legislação psiquiátrica. Uma delas é a publicação, nos $A B P N M L$, de um artigo do professor da cadeira de Medicina Legal da Faculdade de Medicina da Bahia, Raimundo Nina Rodrigues (1862-1906). Intitulado "Legislação sobre assistência a alienados", o artigo de 1906, publicado pouco antes de sua morte, criticava as limitações da lei que, à época, regia o serviço da Assistência, o decreto n. ${ }^{0} 1.132$ de 1903. Este artigo foi rebatido por Juliano Moreira, um dos idealizadores do projeto da lei. Para

\footnotetext{
${ }^{45}$ Cf. CERQUEIRA, op. cit., p. 28-33.

${ }^{46}$ Cf. CERQUEIRA, op. cit., p. 14.
} 


\section{artigos}

\section{O debate legislativo sobre a assistência psiquiátrica na Primeira República}

ele, apesar de suas limitações, era necessário levar em conta seus efeitos positivos para a assistência a alienados ${ }^{47}$.

Nesses textos, o que se pode observar são dois projetos nacionais para a assistência a alienados em disputa: um descentralizador, advogando pelo direito e princípio constitucional federativo de cada estado legislar a partir de suas particularidades com base na experiência estadunidense, defendido por Nina Rodrigues; e outro centralizador, baseado na defesa de uma lei geral inspirada no modelo francês, defendido por Juliano Moreira. Tal disputa coloca em questão mais do que apenas os modelos assistenciais, mas antes, a necessidade de uma tomada de posição quanto ao federalismo, aspecto fundamental para se pensar as prerrogativas do Estado, em suas diferentes instâncias de atuação, frente à assistência ${ }^{48}$.

Em síntese, os argumentos mobilizados por Nina Rodrigues em sua crítica à lei de 1903 estavam ligados ao fato de que, na forma assumida pelo decreto, em muitos momentos a Assistência a Alienados se confundia com o Hospício Nacional. Para o médico,

a fórma de uma lei que se propõe a crear em todo o paiz a protecção legal aos mentecaptos, a marcar para os Estados o typo ou o modelo dos serviços technicos da assistencia aos loucos, não se compadece com o theor do Decreto n. 1132, de 22 de dezembro de 1903, que numa associação lamentavel traz uma mistura no mesmo pé de igualdade, as linhas geraes da legislação penal e civil, relativa aos alienados, prescripções technicas para os estabelecimentos destinados ao tratamento das moléstias mentaes, detalhes do serviço local da assistencia do Districto Federal, e até minudencias do regimento interno do Hospicio Nacional de Alienados. [...] Apenas em 23 artigos, acreditaram os legisladores brazileiros poder condensar todo o plano

\footnotetext{
${ }^{47}$ Sobre as ocorrências da matéria legislação psiquiátrica no interior da SBNPML, ver: CERQUEIRA (2014: p. 153-156).

48 Tomamos conhecimento dos textos onde essas posições são defendidas a partir da dissertação de mestrado de Ede Cerqueira. Ver: CERQUEIRA (2014). Cabe esclarecer que não se trata de um debate propriamente dito, uma vez que Nina Rodrigues vem a óbito pouco tempo depois de publicar seu artigo de críticas à lei de 1903, e a resposta de Juliano Moreira tenha sido publicada apenas um ano mais tarde. Cabe ressaltar ainda que o mesmo texto de Juliano Moreira encontra-se publicado no periódico Brazil-Médico, ano XXI, n. 23, pp. 221-233, de 15 de junho de 1907, tendo sido consultado por nós nesta edição.
} 


\section{artigos}

José Roberto Silvestre Saiol

grandioso da creação da assistencia e da protecção legal aos alienados da República (RODRIGUES, 1906: 303).

Além disso, Nina Rodrigues enfatiza uma série de ambiguidades e imprecisões no texto da lei, bem como seu caráter inconstitucional:

Por conseguinte, desde que, só pelas suas attribuições constitucionnaes de formar o direito pátrio, póde a União influir nos serviços de assistencia a alienados dos Estados, porquanto o encargo de provêr e organisar a assistencia pública é confiada pela Constituição aos governos estaduaes, torna-se claro que a União não poderá encontrar, no mecanismo federativo que foi applicado ao governo da República, meio legal de regular e ficalisar por si a execução das medidas de assistencia a insanos dos Estados, missão essa evidentemente confiada aos poderes estaduaes e em particular á sua magistratura (RODRIGUES, 1906: 307).

Para o autor, um modelo centralizador como o consagrado pela lei de 1903, além de violar as prerrogativas constitucionais dos estados, não daria conta do problema da assistência de maneira eficiente, assim como das particularidades de cada um dos estados da união.

Em seu texto de resposta às críticas de Nina Rodrigues, Juliano Moreira, por sua vez, argumentava que, embora o decreto de 1903 possua alguns problemas, este teria sido importante para colocar em evidência a causa dos alienados. Afirmava ainda a impossibilidade de uma obra jurídica perfeita, enfatizando que o próprio crítico não teria se "aventurado em propor um projeto de lei" (MOREIRA, 1907: 222). Para o então diretor do Hospício Nacional, o "impulso inicial" para a reforma definitiva dos costumes em matéria de assistência a alienados no contexto brasileiro compensaria o pouco mérito do decreto como obra jurídica:

a lei em questão, mesmo sem pretenções a ser perfeita, attingiu o melhor de seu escôpo: <communicar a todo o paiz o movimento generoso em favor dos alienados $>$, tem 0 <intento de garantir os alienados contra as reclusões carcerárias tão em vigor, a intenção positiva de crear uma fiscalisação inexistente até aqui para os estabelecimentos públicos; o sentimento nitido da necessidade de uma 


\section{artigos}

O debate legislativo sobre a assistência psiquiátrica na Primeira República

descriminação nas multiplas fórmas de assistencia a alienados; assim como de serem descriminados das responsabilidades pelo ônus da assistencia aos loucos> (MOREIRA, 1907:221).

Em suma, o argumento de Juliano Moreira se constrói a partir da defesa de uma lei geral para a assistência a alienados que ofereça aos estados da federação as diretrizes básicas para sua organização. Todavia, para uma compreensão mais ampliada de seus argumentos, há que se levar em conta, como vem sendo enfatizado aqui, sua participação bastante ativa no processo de elaboração desta lei, bem como as melhorias materiais realizadas no Hospício Nacional após a sua promulgação.

Já no ano de 1908, a autora afirma que, em uma das reuniões, o Dr. Juliano Moreira teria proposto uma comissão de médicos e advogados para a elaboração de um projeto de reforma do decreto de 1903. O tema da legislação apareceu ainda em outras duas ocasiões: uma em 1912, quando a questão da execução da legislação psiquiátrica foi posta em pauta pela comunicação apresentada por Faustino Esposel; a outra em 1925, quando se decide pela elaboração de um novo projeto para o regulamento da Assistência a ser apresentado ao governo. Novamente, era Juliano Moreira que estava à frente do projeto.

Existe, contudo, outra seção no interior dos Arquivos destinada às notícias nacionais e internacionais no campo da ciência psiquiátrica. Nela, pudemos encontrar durante a análise breves informes acerca da promulgação do decreto n. ${ }^{0} 5.148$ A de 10 de janeiro de 1927, que reorganizava a Assistência aos Psicopatas no Distrito Federal, seguido por sua transcrição ${ }^{49}$.

A dita seção oferece ainda informações sobre o âmbito regional. É o caso, por exemplo, da menção ao Decreto n. ${ }^{\circ}$ 2.215, de 11 de março de 1927, que reorganizava e renomeava a colônia de alienados do estado do Rio de Janeiro, que passou a se chamar Hospital-Colônia de Psicopatas de Vargem Alegre, buscando, assim, adequar o serviço às demandas mais modernas da ciência

\footnotetext{
${ }^{49} A B N P$, ano IX, II-III trimestre, 1927, p. 159.
} 


\section{artigos}

José Roberto Silvestre Saiol

psiquiátrica ${ }^{50}$. No volume seguinte, nova menção é feita a este registro legislativo, desta vez descrevendo em detalhes a reorganização proposta pelo decreto ${ }^{51}$. Ao fim e ao cabo, a análise das atas da SBNPML e das notícias dos ABNP não revelaram detalhes dos debates no interior da Sociedade acerca das propostas legislativas para a assistência psiquiátrica, mas demonstram a presença do tema legislativo nesse espaço científico.

\section{Conclusões}

Nossos esforços se concentraram na investigação dos debates envolvidos no processo de negociação social e política de tramitação e promulgação das leis voltadas para a assistência psiquiátrica no Brasil, no período compreendido entre 1903 e 1927. Pudemos observar assim, de que maneira foram construídos e votados os projetos de lei que regulamentaram a assistência no Brasil, no âmbito da Câmara dos Deputados. Verificamos também que médicos envolvidos em sociedades científicas dedicadas à matéria psiquiátrica circulavam também nos espaços da Câmara, ocupando inclusive cadeiras como deputados ${ }^{52}$.

Vimos também que os projetos de lei propostos nos anos que delimitam nosso recorte temporal preveem a implementação de uma série de mudanças significativas no serviço da assistência. O projeto no 316 de 1903 coloca na ordem do dia a importância de uma legislação voltada para a garantia dos direitos dos alienados, encarados a partir de então como sujeitos de direito, e que deveriam receber, por parte do poder público, uma reparação pela violação de seu direito à liberdade em nome da "tranquilidade social". Cabe notar que algumas das propostas levantadas por este projeto estavam, em certo sentido, colocadas na legislação psiquiátrica do período imperial. Tais continuidades evidenciam-se, por exemplo, na proposição de comissões de inspeção dos asilos da Assistência, visando assim garantir a execução correta das determinações

\footnotetext{
${ }^{50} A B N P$, ano IX, II-III trimestre, 1927, p. 165.

${ }^{51} A B N P$, ano $\mathrm{X}, \mathrm{I}$ trimestre, 1928, p. 38-39.

${ }^{52}$ Como o leitor deve se lembrar, atuaram na elaboração do projeto de lei de 1903 os médicos Juliano Moreira e Teixeira Brandão, este último, à época deputado e relator da CISP; já no ano de 1926, tiveram atuação de destaque Antônio Austregésilo - tanto na proposição do projeto de lei n²95, quanto como relator da Comissão de Saúde do projeto de lei n 218-A - e Afrânio Peixoto, que teria apresentado à citada Comissão de Saúde o projeto da lei de reforma da assistência psiquiátrica.
} 


\section{artigos}

\section{O debate legislativo sobre a assistência psiquiátrica na Primeira República}

legislativas. O projeto $n^{\circ} 218-A$ de 1927 , por sua vez, cujo processo de tramitação contou, em certo sentido, com um número maior de intervenções até a produção final do texto enviado para publicação, parece inaugurar uma espécie de mudança no paradigma da gestão e tratamento da doença mental no Brasil, agora sob o prisma da profilaxia mental.

Cabe destacar ainda que uma das questões centrais no debate de ambos os projetos de lei é a que versa sobre o federalismo e sobre a hierarquia dos Poderes Executivo, Legislativo e Judiciário na implementação de mudanças na Assistência a Alienados em diferentes momentos da Primeira República.

No que se refere à circulação de ideias sobre a legislação psiquiátrica na sociedade científica analisada, não observamos a existência de controvérsias ou de debates acirrados, mas sim a divulgação de propostas que já parecem acordadas para a referida assistência. A única exceção é a posição de Raimundo Nina Rodrigues que, como se sabe, foi um dos principais atores sociais envolvidos no processo de consolidação da medicina legal e da psiquiatria como especialidades médicas. Tendo se debruçado mais de uma vez sobre o tema da legislação para a doença mental ${ }^{53}$, Rodrigues, em seu texto dedicado à crítica da lei de 1903, defende uma posição diversa daquela dos demais membros da Sociedade, insistindo na necessidade de se respeitar o pacto federativo e nos problemas decorrentes da confusão entre o Hospício Nacional e a Assistência a Alienados.

\section{Referências Bibliográficas}

\footnotetext{
53 Outra obra importante do autor sobre essa matéria foi publicada em 1901, sob o título "O alienado no direito civil brasileiro". Nele, o professor de Medicina Legal da Faculdade de Medicina da Bahia reitera a importância das contribuições que os especialistas em alienação mental têm a oferecer aos legisladores, assim como busca propor algumas diretrizes para a inclusão da matéria no código civil brasileiro. Apesar da proximidade temática, não fizemos referência direta a esta publicação porque uma reflexão detalhada acerca da condição civil do alienado excede os limites desse trabalho. Ver: RODRIGUES, Raimundo Nina. O alienado no direito civil brasileiro - Apontamentos médico-legais ao projeto de código civil. Bahia: Prudencio de Carvalho, Editor, 1901. Tomamos conhecimento também de outra publicação sobre a matéria legislativa que será oportunamente consultada: BRANDÃO, João Carlos Teixeira. Questões relativas à assistência médicolegal a alienados. Rio de Janeiro: Imprensa Nacional, 1897.
} 


\section{artigos}

José Roberto Silvestre Saiol

AZEVEDO, Roberto Cesar Silva de. O desfalque, o inquérito e as comissões de inspeção: a assistência a alienados no Brasil (1902-1925). Dissertação (Mestrado) Pontifícia Universidade Católica. Departamento de História. Rio de Janeiro, 2012.

CASA DE OSWALDO CRUZ. Dicionário Histórico-Biográfico das Ciências da Saúde no

Brasil (1832-1930).

Online.

Disponível

em:

http://www.dichistoriasaude.coc.fiocruz.br/iah/pt/index.php.

CERQUEIRA, Ede Conceição Bispo. A Sociedade Brasileira de Neurologia, Psiquiatria e Medicina Legal: Debates sobre ciência e assistência psiquiátrica (1907-1933). Dissertação (Mestrado em História das Ciências e da Saúde) - Casa de Oswaldo Cruz/ Fiocruz, Rio de Janeiro, 2014. 234 f.

"A Sociedade Brasileira de Neurologia, Psiquiatria e Medicina Legal e o seu papel na institucionalização da Psiquiatria (1907-1928). Anais eletrônicos do XXVII Simpósio Nacional de

$\begin{array}{llll}\text { História } & \text { ANPUH } & 2013 . & \text { Disponível }\end{array}$ http://snh2013.anpuh.org/resources/anais/27/1364941724_ARQUIVO_TextocompletoAnpuh2013Ed e.pdf

LUCA, Tania Regina de. Notas sobre os historiadores e suas fontes. Revista Eletrônica Métis. História e Cultura. UCS, v. 11, p. 13-21, 2012.

LUCA, T. R. de; Martins, A. L. Imprensa e cidade 1. Ed. São Paulo, Editora UNESP, 2006. V. 1. 136p.

MOREIRA, Juliano. "A lei federal de Assistência a Alienados e a crítica do professor Nina Rodrigues". Archivos Brasileiros de psychiatria, Neurologia e Medicina Legal, Rio de Janeiro, n. 1. P. 77-97, 1907. "A lei federal de Assistência a Alienados e a crítica do professor Nina Rodrigues". BrazilMédico, ano XXI, n. 23, pp. 221-233.

ODA, Ana Maria Galdini Raimundo; DALGALARRONDO, Paulo. Juliano Moreira: um psiquiatra negro frente ao racismo científico. Rev. Bras. Psiquiatr., São Paulo, v. 22, n. 4, Dec. 2000.

PAZIN, Produção Documental do Legislativo no Império - Gênese e Tipologia: O Caso da Assembleia Legislativa Provincial de São Paulo (1835-1889). Dissertação (Mestrado em História Social) Faculdade de Letras e Ciências Humanas/ Universidade de São Paulo, São Paulo, 2005. 


\section{artigos}

O debate legislativo sobre a assistência psiquiátrica na Primeira República

PINSKY, Carla Bassanezi (Org.). Fontes Históricas. 2. ed. São Paulo: Contexto, 2006.

RODRIGUES, Raimundo Nina. Legislação sobre assistência a alienados. Archivos Brasileiros de psychiatria, Neurologia e Medicina Legal, Rio de Janeiro, ano II, n. 4, 1906. pp. 299-385.

SAIOL, José Roberto Silvestre. "Legislação psiquiátrica no início da República: entre o protagonismo do Hospício Nacional de Alienados e a interiorização da assistência". In: Anais do XVII Encontro de História da Anpuh-Rio: entre o local e o global. Nova Iguaçu, 2016. pp. 01-09.

SODRÉ, Nelson Werneck. História da Imprensa no Brasil. 4. Ed. (atualizada) - Rio de Janeiro: Mauad, 1999.

TEIVE, HÉLIO A G. et al. Professor Antonio Austregésilo: o pioneiro da neurologia e do estudo dos distúrbios do movimento no Brasil. Arq. Neuro-Psiquiatr., São Paulo, v. 57, n. 3B, Sept. 1999.

VENANCIO, Ana Teresa A.; CASSILIA, Janis Alessandra Pereira. A doença mental como tema: uma análise dos estudos no Brasil. Espaço Plural (Unioeste), v.22, p. 24-34, 2010. 